Polymer Journal, Vol. 4, No. 6, pp 657-663 (1973)

\title{
220-MHz NMR Spectra of Butadiene and Acrylonitrile Alternating and Random Copolymers
}

\author{
Toshimitsu Suzuki and Yoshinobu Takegami \\ Department of Hydrocarbon Chemistry, Faculty of Engineering, \\ Kyoto University, Kyoto, Japan. \\ Junji Furukawa \\ Department of Synthetic Chemistry, Faculty of Engineering, \\ Kyoto University, Kyoto, Japan. \\ Eiichi Kobayashi and Yoshihiro Arai \\ Institute for Chemical Research, Kyoto University, Uji, Japan.
}

(Received November 27, 1972)

\begin{abstract}
A 220-MHz NMR investigation was carried out on random and alternating copolymers of butadiene (BD) with acrylonitrile (AN) and partially deuterated analogues of variable composition.

An absorption by the $\mathrm{CH}$ protons of acrylonitrile units in the random copolymer splits into three peaks as the field strength increases. These peaks correspond to AN-AN-AN, BD-AN-AN, and BD-AN-BD triad sequences. The amount of the alternating triad sequence reaches more than $98 \%$ in the alternating copolymer prepared with an $\mathrm{EtAlCl}_{2}-\mathrm{VOCl}_{3}$ catalyst. However, conventional free-radical copolymers have a 77-\% alternating triad sequence (acrylonitrile content $54.2 \%$ ).

Olefin protons of the butadiene units in the random copolymer of BD- $d_{4}-\mathrm{AN}$ appeared as pentad sequences. The pentad sequences centered at butadiene obey firstorder Markov-chain statistics calculated by taking the monomer reactivity ratios as $r_{\mathrm{BD}}=0.35$ and $r_{\mathrm{AN}}=0.05$.

An average conformation estimated from vicinal coupling constant of alternating BD- $d_{4}-\mathrm{AN}$ copolymer shows a slightly distorted trans conformation.

KEY WORDS NMR / Copolymer / Alternating Copolymer / Butadiene / Acrylonitrile / Deuterated Butadiene / Deuterated Acrylonitrile / Sequence Distribution / Markov Chain / Molecular Conformation /
\end{abstract}

In previous papers some of the present authors reported catalytic systems for an alternating copolymerization of butadiene and acrylic monomers, ${ }^{1}$ and also rough characterization of copolymers carried out by means of infrared and $60-\mathrm{MHz}$ and $100-\mathrm{MHz}$ NMR analyses. ${ }^{2}$

A $100-\mathrm{MHz}$ NMR study of alternating and random copolymers of butadiene or isoprene and acrylonitrile was reported by Gaylord, et al., ${ }^{3}$ and the study of isoprene and methyl methacrylate random and alternating copolymers reported by Oikawa, et al. ${ }^{4}$ However, the spectra reported are not sufficiently resolved to discuss the sequence distributions of monomer units and the differences between the $1: 1$ alternating copolymer and that prepared by a free-radical initiator.

In this paper the authors studied $220-\mathrm{MHz}$ NMR spectra of butadiene and acrylonitrile copolymers prepared with conventional freeradical initiators or complexes such as ethylaluminum dichloride together with vanadyl chloride. In addition, an attempt to determine the sequence distribution of the copolymers has been made by using partially deuterated monomers.

\section{EXPERIMENTAL}

\section{Materials}

Butadiene (BD) and acrylonitrile (AN) were 
T. Suzuki, Y. Takegami, J. Furukawa, E. Kobayashi, and Y. Arai

Table I. Copolymerization of butadiene and acrylonitrile or their deuterated analogs

\begin{tabular}{|c|c|c|c|c|c|c|c|}
\hline Expt. no. & Monomer & $\underset{\text { in feed }}{[\mathrm{BD}] /[\mathrm{AN}]}$ & Catalyst & $\underset{{ }^{\circ} \mathrm{C}}{\text { Temp, }}$ & $\underset{\mathrm{hr}}{\text { Time }}$ & $\begin{array}{l}\text { Con- } \\
\text { version, } \\
\%\end{array}$ & $\underset{\substack{[\mathrm{AN}] \text { in } \\
\text { copolymer,a }}}{\text { a }}$ \\
\hline A- 1 & $\mathrm{BD}-\mathrm{AN}$ & $1 / 8.9$ & BPO & 50 & 5 & 11.1 & 59.5 \\
\hline A- 2 & $\mathrm{BD}-\mathrm{AN}$ & $1 / 2.4$ & BPO & 50 & 5 & 18.1 & 49.1 \\
\hline A- 3 & $\mathrm{BD}-\mathrm{AN}$ & $1 / 1$ & BPO & 50 & 5 & 12.5 & 42.9 \\
\hline A- 4 & $\mathrm{BD}-\mathrm{AN}$ & $1 / 2$ & $\mathrm{EtAlCl}_{2}-\mathrm{VOCl}_{3}$ & 0 & 5.7 & 24 & 49.5 \\
\hline$A-5^{b}$ & $\mathrm{BD}-\mathrm{AN}$ & $1 / 2.4$ & $\mathrm{EtAlCl}_{2}-\mathrm{VOCl}_{3}-\mathrm{AlBN}$ & 60 & 12 & 21 & 50.7 \\
\hline A- 6 & $\mathrm{BD}-d_{4}-\mathrm{AN}-d_{1}$ & $1 / 1$ & $\mathrm{EtAlCl}_{2}-\mathrm{VOCl}_{3}$ & 0 & 0.17 & 5.9 & 50.0 \\
\hline A- 7 & $\mathrm{BD}-d_{4}-\mathrm{AN}$ & $1 / 1$ & $\mathrm{EtAlCl}_{2}-\mathrm{VOCl}_{3}$ & 0 & 0.08 & 37 & 49.5 \\
\hline A- 8 & $\mathrm{BD}-d_{4}-\mathrm{AN}$ & $1 / 9$ & BPO & 50 & 2.5 & 16 & 58.5 \\
\hline A- 9 & $\mathrm{BD}-d_{4}-\mathrm{AN}$ & $1 / 2.3$ & BPO & 50 & 4 & 6.8 & 48.6 \\
\hline A-10 & $\mathrm{BD}-d_{4}-\mathrm{AN}$ & $1 / 1$ & BPO & 50 & 5 & 7.1 & 42.3 \\
\hline A-11 & $\mathrm{BD}-d_{4}-\mathrm{AN}$ & $9 / 1$ & BPO & 50 & 72 & 38 & 16.7 \\
\hline
\end{tabular}

a Copolymer composition was calculated from elemental analysis.

b The sample was kindly offered by Mr. K. Irako (Bridgestone Tire Co.).

purified by the usual methods. Ethylaluminum dichloride $\left(\mathrm{EtAlCl}_{2}\right)$ was distilled under reduced pressure and used in an $n$-hexane solution. Vanadyl chloride $\left(\mathrm{VOCl}_{3}\right)$ was used in an $n$ hexane solution. Acrylonitrile- $\alpha-d_{1}\left(\mathrm{AN}-d_{1}\right)$ was prepared according to the method described by Leitch. ${ }^{5} \quad 1,1,4,4-d_{4}$-Butadiene (butadiene- $d_{4}$, BD$d_{4}$ ) was prepared by the method described by Ikeda, et al. ${ }^{6}$

\section{Polymerization Procedures}

Alternating copolymers were prepared as follows; $\mathrm{AN}, \mathrm{BD}, \mathrm{EtAlCl}_{2}$, and $\mathrm{VOCl}_{3}$ were introduced in this order at $-78^{\circ} \mathrm{C}$ into an ampoule flushed with purified nitrogen, and the ampoule was sealed off. After a certain reaction time at $0^{\circ} \mathrm{C}$ the copolymer was precipitated by pouring it into a large amount of methanol. Random copolymers were prepared with benzoyl peroxide (BPO) as the initiator at $50^{\circ} \mathrm{C}$. The polymerization conditions and the results are summarized in Table I.

\section{NMR Spectra}

NMR spectra were obtained using a Varian HR-220 spectrometer. Approximately 5-7-\% $(\mathrm{wt} / \mathrm{vol})$ deuterochloroform solutions of the copolymers were employed with tetramethylsilane as the internal reference. The temperature for the measurements was set at $60^{\circ} \mathrm{C}$. Peak areas were determined by cutting out and weighing xerox copies of the spectrum sheet.

\section{RESULTS AND DISCUSSION}

Butadiene and Acrylonitrile Random and Alternating Copolymers

Figures 1a-1c present 220-MHz NMR spectra of BD-AN random copolymers of different composition prepared with a conventional radical initiator. These spectra are quite similar to the $100-\mathrm{MHz}$ NMR spectra reported by Gaylord, et al. ${ }^{3}$ However, the peaks at around 2.5-3.1 $\delta$ are different from the reported spectra. As shown in Figure 1a, the copolymer has a BD/AN composition of $40.5 / 59.5$, and it is expected from the monomer reactivity ratio that the $\mathrm{AN}$ AN-AN sequence would exist to a considerable extent besides the BD-AN-BD and the AN$\mathrm{AN}-\mathrm{BD}$ sequences. As shown in Figures $1 \mathrm{~b}$ and $1 \mathrm{c}$, on increasing the amount of BD content in the copolymer, the relative intensity of the peaks at 3.05 and $2.87 \delta$ is decreased. Thus, these peaks are assigned to the methine proton of the AN units split by the triad sequences $\mathrm{AN}-\mathrm{AN}-\mathrm{AN}, \mathrm{AN}-\mathrm{AN}-\mathrm{BD}$, and $\mathrm{BD}-\mathrm{AN}-$ BD in accordance with the increases of field strength.

Methylene protons of the BD units in the copolymers appeared at $2.1-2.3 \delta$. With an increase in the BD content in the copolymer, the relative intensity of the peak at $2.12 \delta$ increases, and consequently the peak is assigned to the methylene protons of the $\mathrm{BD}-\mathrm{BD}$ units. In 


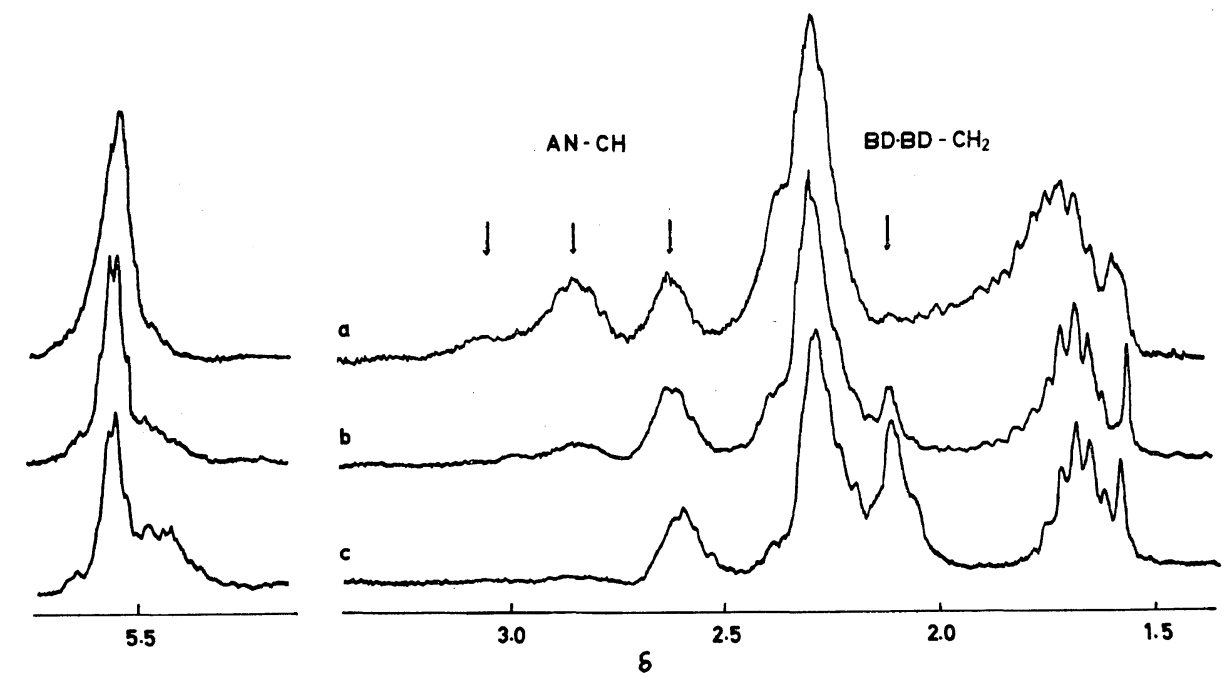

Figure 1. 220-MHz NMR spectra of butadiene-acrylonitrile random copolymers: (a), sample A-1 AN 59.5\%; (b), sample A-2 AN 49.1\%; (c), sample A-3 AN 42.9\%.
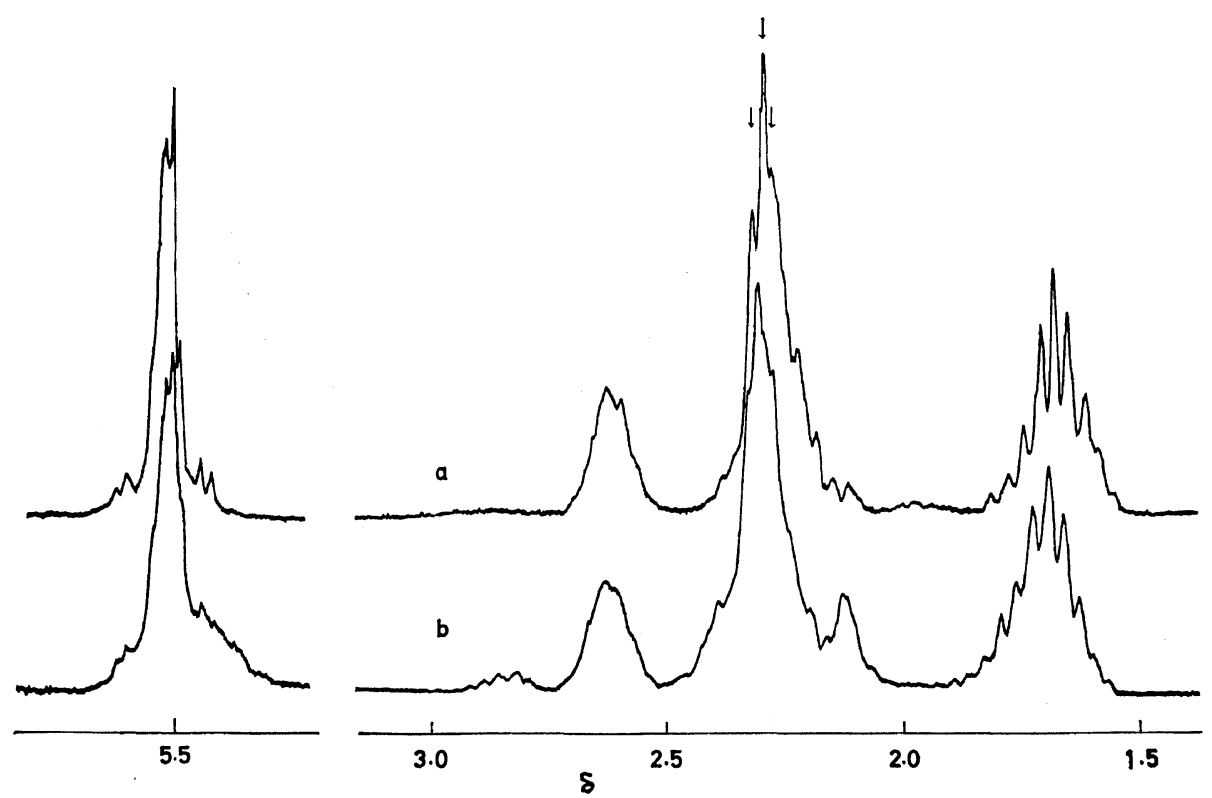

Figure 2. NMR spectra of butadiene-acrylonitrile alternating copolymers: (a), sample A-4; (b), sample A-5. Arrows indicate lower field absorptions of two methylene groups in the butadiene unit.

the previous spectra at 60 or $100 \mathrm{MHz}$ the peak is observed overlapped with the peak at $2.30 \delta$, which is assigned to the methylene protons of BD-AN units.

Olefin protons of BD units appeared at 5.3$5.7 \delta$. The relative intensity of the higher field peaks increases with an increase in the BD units in the copolymer, and this shows that the higher field peak is assigned to the BD-BD-BD sequence and the lower field peak is assigned to the AN-BD-AN sequences. However, these peaks are broadened due to the influence of the monomer arrangements of the neighboring units.

Two Figures $2 a$ and $2 b$ are NMR spectra of 
alternating copolymers prepared by $\mathrm{EtAlCl}_{2}-$ $\mathrm{VOCl}_{3}$ and by $\mathrm{EtAlCl}_{2}-\mathrm{VOCl}_{3}-\mathrm{AIBN}$, respectively. Figure $2 \mathrm{a}$ indicates that the pattern of the spectrum is different from that of the radicalpolymerization copolymer having almost the same composition (Figure 1b).

Figure $2 b$ is different from Figure $2 a$, but is rather close to Figure 1b. From these spectra the dyad fractions are estimated* as follow: For the sample A-4 (Figure 2a) $F_{\mathrm{BB}} 1 \%, F_{\mathrm{AB}} 98 \%$ and $F_{\mathrm{AA}} 1 \%$, and for the sample A-5 (Figure $2 b) F_{\mathrm{BB}} 6.6 \%, F_{\mathrm{AB}} 89.8 \%$, and $F_{\mathrm{AA}} 3.2 \%$. Accordingly, it is concluded that the most regular alternating copolymer is obtained by the polymerization with $\mathrm{EtAlCl}_{2}$ and $\mathrm{VOCl}_{3}$. The addition of AIBN to the above catalyst decreases the alternating regularity of the resulting copolymer so that its regularity is not far from that of a $1: 1$ copolymer made by radical co- polymerization with AIBN alone. This is different from the description in the literature. ${ }^{3}$

The two methylene groups of the BD units flanking the AN units in the alternating sequences show almost the same chemical shift. However, as indicated by the arrows in Figure $2 \mathrm{a}$, the two different multiplet peaks overlap each other. As a first-order approximation, if $\mathrm{H}^{1}$ methylene protons of the BD units are taken to be double doublets, and the coupling constant $J_{\mathrm{H}^{1}-\mathrm{H}^{2}}$ is assumed to be equal to $J_{\mathrm{H}^{1}-\mathrm{H}^{6}}$, the double doublet becomes a triplet. In this spectrum the lower field peaks appear as a triplet, and the higher field peaks are a complex multiplet partially overlapped with the lower field peaks. This suggests that the lower field triplet can be assigned to the $\mathrm{H}^{1}$ methylene protons and the higher field multiplet peaks can be assigned to the $\mathrm{H}^{4}$ methylene protons.

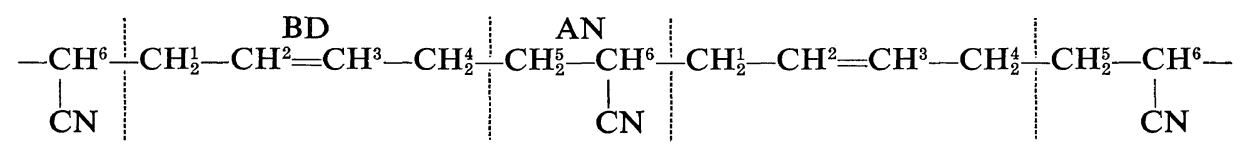

Butadiene- $d_{4}$ and Acrylonitrile- $\alpha-d_{1}$ or Butadiene$d_{4}$ and Acrylonitrile Copolymers

In order to eliminate the peak broadening caused by spin-spin coupling, copolymers containing partially deuterated monomers were prepared by the usual-radical initiator or the complexing agent. In Figure $3 \mathrm{a}$ the NMR spectrum of BD- $d_{4}-\mathrm{AN}-d_{1}$ alternating copolymer is presented. The methylene proton resonances

* The dyad fraction was calculated using the following eq 1-3 from the peak areas and copolymer compositions. The dyad fractions were also calculated from $F_{\mathrm{B}}$ and $F_{\mathrm{BB}}$, but the fractions thus calculated seem to contain more error than those calculated using triad fraction.

$$
\begin{aligned}
& \text { Peak area } \begin{cases}P_{\mathrm{AAA}}=3.05 \delta & F_{\mathrm{AAA}}^{\prime}=\frac{P_{\mathrm{AAA}}}{\sum P} \\
P_{\mathrm{AAB}}=2.87 \delta & F_{\mathrm{BAB}}=2.62 \delta \\
P_{\mathrm{BB}}=2.12 \delta & F_{\mathrm{AAB}}=\frac{P_{\mathrm{AAB}}}{\sum P} \\
P_{\mathrm{BA}}=2.30 \delta & F_{\mathrm{BAB}}^{\prime}=\frac{P_{\mathrm{BAB}}}{\sum P}\end{cases} \\
& F_{\mathrm{BB}}=\frac{P_{\mathrm{BB}}}{P_{\mathrm{BB}}+P_{\mathrm{AB}}} F_{\mathrm{B}} \\
& F_{\mathrm{AA}}=\left(F_{\mathrm{AAA}}^{\prime}+(2 / 1) F_{\mathrm{AAB}}^{\prime}\right) F_{\mathrm{A}} \\
& F_{\mathrm{AB}}=\left(F_{\mathrm{BAB}}^{\prime}+(1 / 2) F_{\mathrm{AAB}}^{\prime}\right) F_{\mathrm{A}}+\frac{P_{\mathrm{AB}}}{P_{\mathrm{BB}}+P_{\mathrm{AB}}} F_{\mathrm{B}}
\end{aligned}
$$

of the $\mathrm{AN}$ units at $1.56 \delta$ are split into an $\mathrm{AB}$ quartet, showing the nonequivalence of the two methylene protons $\left(J_{\mathrm{AB}}=-13.1 \mathrm{~Hz}, \nu_{\mathrm{A}}-\nu_{\mathrm{B}}=\right.$ $16.3 \mathrm{~Hz})$. It is reported that the methylene protons of polyacrylonitrile in a meso dyad exhibit nonequivalence depending on the solvent used for measurement of the NMR spectrum. ${ }^{7}$ The nonequivalence of methylene protons in the vinyl monomer unit was already observed in the alternating copolymers of butadiene and propylene. ${ }^{8}$ Oikawa, et al., reported the nonequivalence of methylene protons in isoprene units adjacent to the quarterly carbon of methyl methacrylate units in the alternating copolymers of isoprene and methyl methacrylate. ${ }^{4}$

Figure $3 b$ shows an NMR spectrum of the BD- $d_{4}-\mathrm{AN}$ alternating copolymer. The methylene protons of the $A N$ units appear as the $A B$ part of an ABX spin system. Using $J_{\mathrm{AB}}=-13.1 \mathrm{~Hz}$, obtained from sample A-6, $J_{\mathrm{AX}}$ and $J_{\mathrm{Bx}}$ were obtained from a trial and error method by fitting the calculated and observed spectra (line position and intensity ratio of the AB part). The NMR parameters obtained are as follows: $J_{\mathrm{AX}}=8.5 \mathrm{~Hz}, J_{\mathrm{BX}}=5.0 \mathrm{~Hz}$, and $J_{\mathrm{AB}}=$ 13.1 Hz. The Relatively large differences in $J_{\mathrm{AX}}$ 


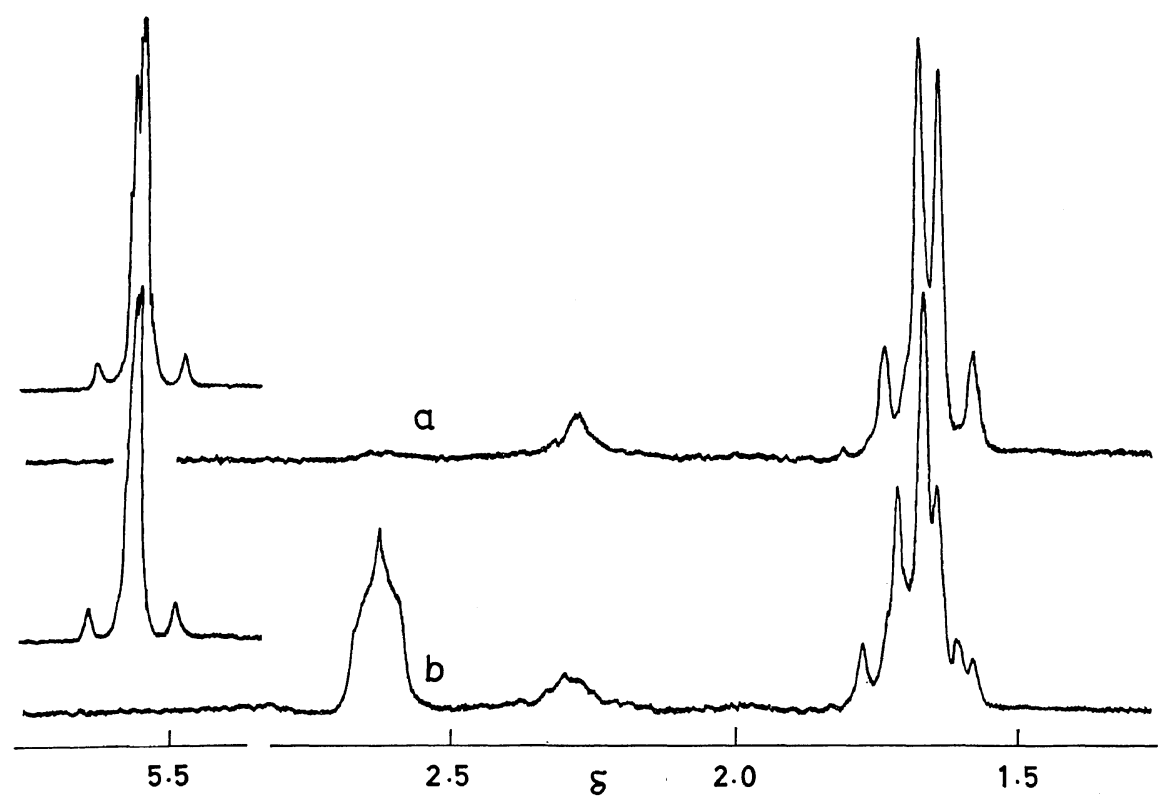

Figure 3. NMR spectra of butadiene- $d_{4}-$ acrylonitrile- $d_{1}$ alternating copolymer (a) and butadiene- $d_{4}-$ acrylonitrile alternating copolymer (b).



Figure 4. Average conformation of butadiene$d_{4}-$ acrylonitrile alternating copolymer.

and $J_{\mathrm{BX}}$ show that the conformation of this copolymer is mainly of the trans form. An estimated average conformation calculated from the Karplus' equation ${ }^{9}$ is shown in Figure 4. The molecular model indicated in Figure 4 shows a nonplanar zigzag and somewhat twisted conformation as already mentioned in a preceding report $^{10}$ on infrared and X-ray studies. The methine proton resonance should consist of six lines. However, as shown in the spectrum in Figure 3b, only a broad envelope of separated lines can be observed. Two possibilities* for

* A referee kindly suggested the possibility of an $\mathrm{H}-\mathrm{D}$ coupling. However, as shown in Figure $3 \mathrm{~b}$ the methylene part of this copolymer is clearly split, and further as shown in Figure 2a, the methine proton of the AN unit of the copolymer containing undeuterated butadiene show the same pattern. Therefore, this possibility seems not to be important. the broadening of the methine proton resonance are considered. One is the possibility that the alternating sequences are disordered by the occurrence of $\mathrm{BD}-\mathrm{BD}$ or $\mathrm{AN}-\mathrm{AN}$ sequences, resulting in a slight chemical shift differences in the pentad arrangement. The other possibility exists if the configuration of AN units is not regular, thus resulting in chemical shift differences according to alternating tactic or atactic placement. The former possibility may be ruled out by the fact that the absorption by methine proton is predominantly due to the $\mathrm{BD}-\mathrm{AN}$ BD triad and as discussed below the resonances of olefin protons of the BD unit gave essentially a single peak. From the nonequivalence of methylene protons of isoprene units, Oikawa, et al., proposed $^{4}$ a regular configuration for their alternating copolymer of isoprene and methyl methacrylate. Although resonances of methylene protons in the alternating copolymer of BD-AN show distinctly an $\mathrm{AB}$ pattern, the latter possibility of the broadening of the methine proton absorption is plausible.

Considering the magnitude of the magnetic anisotropy of the nitrile group, the chemical shifts of $\mathrm{H}_{A}^{5}$ and $\mathrm{H}_{\mathrm{A}}^{5 \prime}$ in methylene protons of two AN units may be different, when the 




Figure 5. Chain configuration of butadieneacrylonitrile alternating copolymer.

configuration of this copolymer is not regular as illustrated in Figure 5. However, the magnetic anisotropy effects of carbon-carbon double bonds and the skeletal effects on $\mathrm{H}_{\mathrm{A}}^{5}$ and $\mathrm{H}_{\mathrm{B}}^{5}$ or $\mathrm{H}_{\mathrm{A}}^{5 \prime}$ and $\mathrm{H}_{\mathrm{B}}^{5 \prime}$ can not be estimated. Accordingly, it is possible that the chemical shifts of these protons become as follows: $\mathrm{H}_{\mathrm{A}}^{5}=\mathrm{H}_{\mathrm{B}}^{5 \prime}$ and $\mathrm{H}_{\mathrm{B}}^{5}=\mathrm{H}_{\mathrm{A}}^{5 \prime}$. Therefore the broadening of absorption of the methine proton of AN units may be ascribed to the occasional irregularity of an AN configuration.

NMR spectra of BD- $d_{4}-\mathrm{AN}$ copolymers of different composition prepared with the radical initiator are shown in Figure 6. The olefin proton absorptions consist of several peaks, partly overlapping each others. With increasing BD content in the copolymer, the intensity of the higher field peaks increases. This means that the absorption of olefin protons in the BD units shifts upfield when the central BD unit is surrounded with BD units. The olefin proton absorption appears as eight peaks at $5.29-5.68 \delta$.
The assignments of these peaks were made as shown in the first column of Table II. The assignments are essentially based on pentad sequences of centered butadiene, although contributions by occasional hetero linkages such as a butadiene 1,2-unit can not be rule out.

Providing that $r_{\mathrm{BD}}$ and $r_{\mathrm{AN}}$ are 0.35 and 0.05 , respectively, the sequence distribution of the pentad was calculated according to the equation proposed by Ito and Yamashita. ${ }^{11}$ Although the accuracy of determining the spectrum peak area is not high, there is considerable agreement between the calculated and observed sequence distributions. According to Gaylord, et al. ${ }^{3}$ the alternating copolymer and a $1: 1$ radical copolymer are not distinguishable in $100-\mathrm{MHz}$ NMR spectra. However, in our result the NMR spectra of sample A-7 (Figure $3 b$ ) and sample A-9 (Figure 6b) or A-10 (Figure 6c) are remarkably different, showing a high concentration of alternating sequences in sample A-7. Sample A-11, with a high concentration of BD units, contains more than $10 \%$ of 1,2-linkages of BD units. This causes an improper assignment of pentad sequences, resulting in a disagreement between calculated and observed sequence distributions.

Triad sequences centered at a AN unit of these copolymers can be obtained from the resonances



Figure 6. NMR spectra of butadiene- $d_{4}$-acrylonitrile copolymers: (a), sample A-8 AN 58.5\%; (b), sample A-9 AN 48.6\%; (c), sample A-10 AN 42.3\%. 
Table II. Sequence distribution of butadiene- $d_{4}-$ acrylonitrile copolymers $^{\mathrm{a}}$

\begin{tabular}{|c|c|c|c|c|c|c|c|c|c|}
\hline & & \multicolumn{2}{|c|}{ A-8 } & \multicolumn{2}{|c|}{ A-9 } & \multicolumn{2}{|c|}{ A-10 } & \multicolumn{2}{|c|}{ A-11 } \\
\hline \multicolumn{2}{|c|}{ AN content, $\%$} & $\begin{array}{l}\text { Calcd, } \\
58.3\end{array}$ & $\begin{array}{l}\text { Obsd, } \\
58.5\end{array}$ & $\begin{array}{l}\text { Calcd, } \\
49.3\end{array}$ & $\begin{array}{l}\text { Obsd, } \\
48.6\end{array}$ & $\begin{array}{l}\text { Calcd, } \\
43.8\end{array}$ & $\begin{array}{l}\text { Obsd, } \\
42.3\end{array}$ & $\begin{array}{l}\text { Calcd, } \\
20.3\end{array}$ & $\begin{array}{l}\text { Obsd, } \\
16.7\end{array}$ \\
\hline Peak, $\delta$ & Sequence & & & & & & & & \\
\hline 2.62 & BAB & 0.45 & 0.48 & 0.80 & 0.77 & 0.89 & 0.90 & 0.99 & 1.00 \\
\hline 2.87 & BAA & 0.42 & 0.43 & 0.19 & 0.23 & 0.09 & 0.11 & 0.01 & 0 \\
\hline 3.05 & AAA & 0.13 & 0.10 & 0.01 & $\sim 0$ & 0.01 & 0 & 0 & 0 \\
\hline 5.29 & BBBBB & 0 & 0 & 0 & 0 & $\sim 0$ & 0 & 0.33 & 0.32 \\
\hline 5.32 & ABBBB & $\sim 0$ & 0 & $\sim 0$ & 0 & 0.03 & 0.03 & 0.21 & 0.38 \\
\hline 5.35 & ABBBA & $\sim 0$ & 0 & 0.01 & 0.02 & 0.04 & 0.02 & 0.03 & 0 \\
\hline 5.38 & BBBAB & $\sim 0$ & 0 & 0.03 & 0.08 & 0.09 & 0.15 & 0.23 & 0.12 \\
\hline 5.40 & $\left\{\begin{array}{l}\text { BBBAA } \\
\text { ABBAB }\end{array}\right.$ & $\begin{array}{l}\sim 0 \\
0.05\end{array}$ & 0.07 & $\begin{array}{l}\sim 0 \\
0.18\end{array}$ & 0.15 & $\begin{array}{l}\sim 0 \\
\quad 0.27\end{array}$ & 0.17 & $\begin{array}{l}0.01 \\
0.08\end{array}$ & 0.13 \\
\hline 5.49 & ABBAA & 0.02 & 0.04 & 0.02 & - & 0.02 & - & 0.01 & - \\
\hline 5.56 & BABAB & 0.44 & 0.55 & 0.61 & 0.60 & 0.49 & 0.54 & 0.05 & 0.05 \\
\hline 5.61 & $\mathrm{AABAB}$ & 0.40 & 0.27 & 0.14 & 0.12 & 0.05 & 0.03 & $\sim 0$ & 0 \\
\hline 5.68 & AABAA & 0.09 & 0.07 & 0.08 & 0.02 & 0.01 & 0.05 & $\sim 0$ & 0 \\
\hline
\end{tabular}

a Calcd: AN composition and sequence distribution were calculated from monomer reactivity ratios using the Lewis-Mayo equation and that proposed by Ito and Yamashita. ${ }^{11}$ Obsd: AN composition was obtained from elemental analyses. Sequence distributions were obtained from NMR peak area of indicated values.

of methine protons of AN units. The calculated and observed sequence distributions of this triad are also in good agreement as shown in Table II.

These results clearly show that the radical copolymerization of $\mathrm{BD}$ and $\mathrm{AN}$ initiated by BPO obeys first-order Markov-chain statistics. On the other hand, the copolymerization initiated by the $\mathrm{EtAlCl}_{2}$ and $\mathrm{VOCl}_{3}$ catalyst is completely different in nature, giving a copolymer with a very high degree of alternation sequence. However, there are deviations from regular sequence distribution in the alternating copolymer due to various reasons. These variations may be solved through a quantitative analysis of small amounts of the homosequence. This problem will be discussed in a subsequent report.

\section{REFERENCES}

1. J. Furukawa, E. Kobayashi, and Y. Iseda, Bull. Inst. Chem. Res., Kyoto Univ., 47, 222 (1968), Polymer J. 1, 155 (1970); J. Furukawa, E. Kobayashi, Y. Iseda, and Y. Arai, ibid., 1, 442 (1970).
2. J. Furukawa, Y. Iseda, K. Haga, and N. Kataoka, J. Polym. Sci., Part A-1, 8, 1147 (1970).

3. B. Patnaik, A. Takahashi, and N. G. Gaylord, J. Macromol. Sci.-Chem., A4, 143 (1970).

4. E. Oikawa and K. Yamamoto, Polymer J., 1, 669 (1970).

5. L. C. Leitch, Can. J. Chem., 35, 345 (1957).

6. A. Yamamoto, K. Morifuji, S. Ikeda, T. Saito, Y. Uchida, and A. Misono, J. Amer. Chem. Soc., 90, 1878 (1968).

7. K. Matsuzaki, T. Uryu, M. Okada, and H. Shiroki, J. Polym. Sci., Part A-1, 6, 1475 (1968); W. M. Ritchey and F. J. Knoll, ibid., Part B, 4, 853 (1966).

8. T. Suzuki, Y. Takegami, J. Furukawa, and R. Hirai, ibid., Part B, 9, 931 (1971).

9. M. Karplus, J. Amer. Chem. Soc., 85, 2870 (1963).

10. J. Furukawa, E. Kobayashi, K. Uratani, Y. Iseda, J. Umemura, and T. Takenaka, Polymer J., 4, 358 (1973).

11. K. Ito and Y. Yamashita, J. Polym. Sci., Part $A-1,3,2165$ (1965). 